\title{
AS CONTRIBUIÇÕES DA PSICANÁLISE À EDUCAÇÃO
}

\author{
THE CONTRIBUTIONS OF PSYCHOANALYSIS TO EDUCATION
}

\section{Margaret Pires do Couto*}

\section{RESUMO}

Este texto discute as contribuições da psicanálise à educação e recolhe dos textos freudianos e lacanianos alguns conceitos que podem auxiliar na elucidação do fenômeno educativo. $\mathrm{O}$ trabalho enfatiza, nessa interlocução, a dimensão do impossível e a lógica do inconsciente na cena escolar.

PALAVRAS-CHAVE: Psicanálise. Educação. Inconsciente. Impossível.

\section{ABSTRACT}

The text discusses the contributions of psychoanalysis to education and collate from the Freudian and Lacanian texts some concepts that may assist in the elucidation of the educational phenomenon. Emphasized this interlocution the extent of the impossible and the logic of the unconscious in the school scene.

KEY WORDS: Psychoanalysis. Education. Unconscious. Impossible.

Freud não se dedicou diretamente ao tema da educação. Entretanto, encontramos em sua obra diversas passagens, indagações e reflexões que nos oferecem elementos para pensar o fenômeno educativo.

Encontramos elementos importantes de articulação entre a psicanálise e a educação em alguns textos freudianos, entre eles: "Contribuições para uma Discussão acerca do Suicídio" (1910), "Interesse educacional da Psicanálise” (1913), "Introdução ao Método Psico-Analítico de Pfister" (1913), “Algumas Reflexões sobre a Psicologia do Escolar” (1914), "Prefácio à Juventude Desorientada de Aichhorn" (1925), apenas para citar os mais conhecidos.

Uma das articulações entre esses dois campos de conhecimento é bastante conhecida e refere-se à formulação freudiana acerca dos efeitos da educação na doença nervosa. No texto “Moral Sexual 'Civilizada' e Doença Nervosa” (1908), Freud parte da ideia de que a educação seria uma das principais causadoras da neurose por meio do mecanismo da repressão. Nos primórdios de sua elaboração teórica, Freud defendia uma espécie de educação esclarecida pela psicanálise acreditando poder realizar uma profilaxia das neuroses, ou seja, a

\footnotetext{
* Doutora em Educação pela Faculdade de Educação da Universidade Federal de Minas Gerais (FaE/UFMG). Psicanalista e professora do Curso de Psicologia do Centro Universitário Newton Paiva. E-mail: coutomargaret@gmail.com.
} 
educação deveria promover uma reforma em suas bases evitando a severidade nos assuntos sexuais.

Porém essa formulação freudiana não se sustentou por muito tempo, e Freud introduziu o impossível no campo da educação. Impossível que tem relação com o ineducável das pulsões, com a dimensão do gozo, ou com termos lacanianos como o Real, que será retomado mais adiante.

Assim, podemos extrair do arcabouço conceitual psicanalítico conceitos e elaborações teóricas que podem ajudar-nos a ler os fenômenos educativos e os impasses que decorrem daí.

\section{SABER E PULSÃO}

Uma dessas elaborações diz respeito à dimensão pulsional do saber. Diferentemente de outras teorias sobre a aprendizagem, a psicanálise interessa-se pelas relações do saber com o desejo e o gozo.

Dizer que o saber é pulsional é dizer que ele tem origem no corpo. No texto "Sobre as Teorias Sexuais das Crianças (1908)", Freud discute o que move o sujeito a saber e conclui que esse movimento é impulsionado pela tentativa de elucidação da diferença a partir do encontro com a diferença sexual anatômica. Essa diferença, impossível de ser totalmente simbolizada uma vez que a anatomia não dará conta de respondê-la, permanecerá para o sujeito como um enigma e exigirá dele alguma construção a fim de que possa se localizar na partilha entre os sexos.

Outros enigmas também movimentarão o sujeito em sua elaboração de saber. Temos, assim, o enigma da origem e da filiação, ou seja, a pergunta, perturbadora para o sujeito, acerca da origem dos bebês e do desejo que uniu aqueles que lhe deram origem. Além disso, o enigma que envolve a morte e a finitude também movimenta o sujeito em sua busca de saber, uma vez que o conduz à pergunta sobre o sentido da existência - se haveria algum e, se sim, como encontrá-lo.

As sensações no corpo, responsáveis por satisfações autoeróticas, recebidas pelo sujeito a princípio como estranhas, no sentido de estrangeiras, também movem o sujeito em sua pesquisa e em suas elaborações. Esses enigmas ganham a forma de uma curiosidade sexual que poderá desdobrar-se em uma profícua curiosidade intelectual, dependendo dos destinos que a pulsão aí encontrar. É desse movimento de pesquisa e elaboração de saber que Freud supõe originar o desejo de saber, motor da aprendizagem. 
Lacan, por sua vez, indicará como é também daí que se produzirá uma espécie de paixão, a paixão pela ignorância. As satisfações pulsionais advindas do corpo produzem um gozo impossível de ser dito. Diferentes consequências para o saber podem advir dessa relação com o gozo, como uma busca apaixonada pelo sentido ou uma espécie de fixidez de algum sentido. Desse gozo de que o sujeito nada sabe, eterniza-se a busca por um saber capaz de dizê-lo. O resultado disso seria uma impotência em relação ao saber (LAURENT, 2000).

\section{TRANSFERÊNCIA E APRENDIZAGEM}

Outra contribuição importante que a psicanálise pode oferecer ao campo da educação diz respeito a como a relação professor-aluno constitui-se como um campo de transferências. Nesse sentido, entre esses dois atores do espaço escolar, entra em jogo um campo de forças que se atraem e se repelem. Tal como ocorre na experiência analítica - na qual a transferência pode se apresentar como motor do tratamento ou obstáculo a ele -, também na relação professor-aluno, a transferência pode facilitar/permitir ou dificultar/impedir a aprendizagem.

Desse modo, a educação desenvolve-se mais pelo laço que se estabelece com esse outro do saber do que pelo conhecimento adquirido. Esse enlaçamento, também pulsional, exige que introduzamos na cena escolar a subjetividade de quem ensina e de quem aprende. Movimento contrário ao discurso pedagógico contemporâneo, que, por sua vez, visa esvaziar o espaço da subjetividade do professor tentando reduzi-lo a um técnico, dessubjetivado, transmissor de conhecimentos sem escolhas, história ou posições definidas.

$\mathrm{Na}$ transferência, o professor é convocado a ocupar um lugar marcado por investimentos libidinais. De acordo com Freud (1914/1969), ele substitui as figuras parentais, figuras de autoridade e/ou pessoas que lhe foram importantes em relação ao saber. Desse modo, pode-se afirmar, a partir da psicanálise, que aprender implica colocar o Outro em uma posição especial conferida pelo inconsciente. Sendo assim, a autoridade do professor não é imposta, mas outorgada a ele pelo próprio aluno. Portanto, a noção de transferência conjuga saber, autoridade e poder.

O sintagma Sujeito Suposto Saber, proposto por Lacan (1960/1992), permite elucidar essa conjugação. Ao reler Freud, Lacan ressaltará a importância da transferência, afirmando que aí reside todo o segredo de um tratamento. Acrescentamos que, quanto à relação professor-aluno, é aí também, no manejo da transferência, que reside o segredo da 
aprendizagem. No que diz respeito ao mecanismo da transferência amorosa, declara que aí estaria em jogo o amor que se dirige ao saber, animando, assim, o desejo de saber do sujeito.

Por outro lado, enquanto um obstáculo ao saber, a transferência, em sua vertente de atualização da realidade sexual do inconsciente, pode tornar atual ou colocar em ato algo de outra cena, algo traumático (LACAN, 1964/1998). Nesse sentido, a cena educacional pode propiciar a atualização de traumas - algo do campo do excesso pulsional que se tornou insuportável para o sujeito -, e isso pode dificultar a aprendizagem.

A psicanálise, assim, enfatiza a transferência como mola propulsora na tarefa educativa em detrimento dos métodos e inovações tecnológicas, que, apesar de terem sua importância, não são suficientes para o ato de ensinar.

\section{O CONCEITO DE SINTOMA}

Outro conceito de grande valia para o campo da educação é o de sintoma. Diferentemente do discurso médico, no qual o sintoma é interpretado como sinal de uma patologia, na psicanálise, o sintoma é considerado uma solução encontrada pelo sujeito diante de situações de impasse. O sintoma é tomado então como solução que tem uma função para o sujeito e não simplesmente como uma disfunção que deverá ser eliminada a qualquer custo.

Nessa perspectiva, o sintoma tem a função de proteger o sujeito de um excesso pulsional que provoca mal-estar e angústia. Tanto Freud quanto Lacan farão uma extensa conceituação do sintoma em diferentes momentos de seu ensino. Freud acentua o sentido que o sintoma tem; segundo ele, o sintoma pode ser interpretado pelo próprio sujeito a fim de encontrar sua verdade inconsciente, além de representar uma satisfação pulsional não reconhecida pelo sujeito como satisfação, mas como produtora de sofrimento (FREUD, 1917/1969).

Para Lacan, ao retomar e fazer avançar o pensamento freudiano, o sintoma é o signo do que não anda, ou seja, sinaliza exatamente o que não funciona e, por outro lado, constituise como um modo de tratamento disso que tropeça. O sintoma torna-se um parceiro na lida do sujeito com o Real insuportável, transformando-se em uma espécie de ferramenta (MILLER, 2008).

De problema a solução, de obstáculo a parceiro é esse paradoxo encontrado no sintoma que orienta a psicanálise em uma ética diferente da simples eliminação desse ente aparentemente indesejável. O conceito de sintoma em psicanálise conduz-nos a ler o 
sofrimento do sujeito na cena escolar não necessariamente como déficit, transtorno ou incapacidade, mas como solução para seu impasse subjetivo com o saber.

O desconhecimento dessa dimensão subjetiva do sintoma tem como efeito o excesso de ofertas de nomeações que silenciam o sujeito e segregam-no por meio de classificações psicopatológicas e de transtornos os mais diversos. Em função de um ideal de adaptação escolar, predomina, na contemporaneidade, uma tendência a universalizarem-se os impasses que cada um experimenta, de modo particular, durante seu processo de escolarização.

Além disso, pensar a dificuldade escolar como um sintoma é reconhecer sua dimensão de impossível, ou seja, reconhecer aquilo que insiste e persiste mesmo diante das iniciativas pedagógicas, médicas ou psicológicas de eliminar, silenciar ou domesticar tais dificuldades.

\section{ATO EDUCATIVO E LAÇO SOCIAL}

Em "O futuro de uma ilusão" (1927/1969), Freud afirma que a finalidade da educação é a instauração do princípio de realidade, ajudando a criança a renunciar ao seu modo de funcionamento quase todo submetido ao princípio de prazer. A tarefa educacional possibilita, assim, a entrada da criança no discurso por meio da renúncia às satisfações imediatas, ou seja, ao gozo. Por inserir a criança em um espaço de confrontação de subjetividades, a entrada na escola implica aceitar as obrigações e regras do laço escolar, que prepara o sujeito para a vida em sociedade.

Nesse sentido, a educação poderá auxiliar no processo de sublimação, desviando os interesses e satisfações imediatos do sujeito em direção a outro alvo e objeto, mediado pelo Outro e pela cultura. $\mathrm{O}$ ato educativo opera, desse modo, a passagem da pura satisfação das pulsões para um universo simbólico.

Ademais, ao oferecer ao sujeito o conhecimento socialmente construído, a escola, além de ser um espaço de socialização, torna-se um lugar de construção de laços com o saber, com o outro da cultura e com os discursos organizados. Ao estar em um lugar de enlaçamentos, o sujeito pode encontrar, no espaço educativo, algo em que possa se engajar, encontrando e/ou inventando seu lugar no mundo. 


\section{A DIMENSÃO DO IMPOSSÍVEL}

Entretanto, pode-se afirmar que a principal contribuição da psicanálise à educação seria a introdução de um impossível na cena educativa.

Em “Análise terminável e interminável” (1937/1969), Freud retoma a afirmação já realizada em "Prefácio à Juventude Desorientada de Aichhorn" (1925/1969) segundo a qual a prática educativa seria um ofício impossível, ao lado das tarefas de analisar e governar afirmação emblemática para aqueles que se dedicam ao campo de interlocução entre a psicanálise e a educação, interlocução essa que, entretanto, merece ser mais bem discutida. Dizer que educar é impossível não é desmerecer ou diminuir a importância do ato educativo, mas apontar que há algo nesse ato que esbarra em uma impossibilidade, permanecendo sempre um resto dessa operação, um inatingível. Além disso, significa dizer que educar não é suficiente para a aprendizagem, uma vez que apreender exige uma operação ativa de buscar algo - o saber no campo do Outro.

É por meio dessa perspectiva que, a partir da psicanálise, podemos diferenciar educação de transmissão. Educar vem do latim ensinare, en-signar e refere-se à ação de colocar em signos, o que exige uma intencionalidade consciente e deliberada na direção de passar certa significação. Transmitir, por outro lado, indica algo que passamos adiante à nossa revelia, como uma transmissão de um vírus, denotando, assim, a ausência de intenção inconsciente (VOLTOLINI, 2011).

Dessa maneira, o que a psicanálise nos ensina é que a pretensão de mestria educativa esbarra em um limite, em um fato de estrutura, qual seja, a própria estrutura da linguagem que inclui um impossível de dizer. Sempre dizemos mais ou menos do que gostaríamos de dizer é o que Lacan nos ensina.

Encontramos, portanto, na cena escolar, o sinal daquilo que escapa à operação da educação, um impossível, um ineducável, responsável pela insistência dos sintomas a qual constitui obstáculo ao cumprimento das exigências e ideais educativos. Podemos pensar então o ineducável na educação como um índice daquilo que o ideal não consegue recobrir, ou seja, o caráter conflitivo e paradoxal da sexualidade humana, da pulsão e do gozo. Esse ineducável que faz limite às exigências superegoicas e ideais civilizatórios revela a presença de algo na subjetividade humana que resiste a qualquer tentativa de domínio e de controle e, portanto, torna-se refratário à ação educativa. 
A psicanálise propõe então que tomemos a educação como uma arte - no sentido de uma invenção para se fazer com esse impossível - versus uma técnica, que se orientaria por um conjunto de procedimentos já pré-definidos. Além disso, a psicanálise nos ensina a fazer do impossível o motor da ação educativa diante da impotência que pode insurgir entre os educadores.

\section{OS IMPASSES COM O SABER NO MUNDO CONTEMPORÂNEO}

Para finalizar, torna-se fundamental tecer algumas considerações sobre as contribuições da psicanálise acerca do saber no mundo contemporâneo.

Para a psicanálise, o mundo contemporâneo tem como característica central um empuxo ao gozo, ou seja, a busca pela satisfação imediata com os objetos do mundo, dispensando-se, na maioria das vezes, o Outro. Encontramos, na contemporaneidade, a produção e a oferta de objetos que prometem satisfação total, fazendo prevalecer o campo do gozo, marcado pelo excesso, em relação ao campo do desejo, orientado pela falta. Deparamonos também com a tentativa de eliminar a falta e, por isso, com o rechaço da dimensão do impossível. Tudo se torna possível, sem limites (MILLER, 2005).

Tudo isso produz efeitos para a relação com o saber. Impera então, no mundo contemporâneo, a busca por um saber rápido, que procura responder tudo imediatamente e de forma universal. O mercado torna-se o agente no laço entre o sujeito e o conhecimento. A aquisição de conhecimento deixa de estar do lado da construção de saberes e passa a operar como ferramenta para competir por um lugar no mercado.

Enfrentamos também a tirania do saber aliada ao novo senhor que é o capital. Trata-se da transformação da educação em bem de consumo, e, consequentemente, observa-se a retirada desse ato de sua condição simbólica.

Impera também a ausência de suposição de saber no Outro, suporte da transferência, suposição essa que permite ao aprendiz buscar no Outro, educadores e mestres, o saber que lhe falta. Ao contrário, no mundo contemporâneo, acredita-se que o saber estaria no bolso, facilmente encontrado nos aparelhos eletrônicos e na internet. Tal posição desvela bem o desvanecimento do simbólico e a dissolução do laço social.

Enfim, a interlocução da psicanálise com a educação não visaria à sobreposição desses dois campos de saber e dos objetivos e ações de cada um, mas, sim, incluir o sujeito do inconsciente e sua lógica na cena escolar e indicar os limites da ação educativa sobre o gozo. 
Somente assim, professor e aprendiz podem promover um bom encontro que permita a cada um produzir uma solução, sob medida, para os impasses subjetivos.

\section{REFERÊNCIAS}

FREUD, Sigmund (1908). Moral sexual "civilizada" e doença nervosa moderna. In: FREUD, Sigmund. Edição standard brasileira das obras psicológicas completas de Sigmund Freud, vol. IX). Rio de Janeiro: Imago, 1969, p. 183-208.

FREUD, Sigmund (1908). Sobre as teorias sexuais das crianças. In: FREUD, Sigmund. Edição standard brasileira das obras psicológicas completas de Sigmund Freud, vol. IX. Rio de Janeiro: Imago, 1969, p. 209-228.

FREUD, Sigmund (1910). Contribuições para uma discussão acerca do suicídio. In: FREUD, Sigmund. Edição standard brasileira das obras psicológicas completas de Sigmund Freud, vol. XI. Rio de Janeiro: Imago, 1969, p. 217-218.

FREUD, Sigmund (1913). Introdução ao método Psico-analítico de Pfister. In: FREUD, Sigmund. Edição standard brasileira das obras psicológicas completas de Sigmund Freud, vol. XII. Rio de Janeiro: Imago, 1969, p. 413-418.

FREUD, Sigmund (1913). O interesse educacional da psicanálise. In: FREUD, Sigmund. Edição standard brasileira das obras psicológicas completas de Sigmund Freud, vol. XIII. Rio de Janeiro: Imago, 1969, p. 224-226.

FREUD, Sigmund (1914). Algumas reflexões sobre a Psicologia Escolar. In: FREUD, Sigmund. Edição standard brasileira das obras psicológicas completas de Sigmund Freud, vol. XIII. Rio de Janeiro: Imago, 1969, p. 281-288.

FREUD, Sigmund (1917). O sentido do sintoma. In: FREUD, Sigmund. Edição standard brasileira das obras psicológicas completas de Sigmund Freud, vol. XVI. Rio de Janeiro: Imago, 1969. p. 305-322.

FREUD, Sigmund (1925). Prefácio à Juventude Desorientada, de Aichhorn. In: FREUD, Sigmund. Edição standard brasileira das obras psicológicas completas de Sigmund Freud, vol. XIX. Rio de Janeiro: Imago, 1969, p. 341- 348.

FREUD, Sigmund (1927). O futuro de uma ilusão. In: FREUD, Sigmund. Edição Standard Brasileira das Obras Completas de Sigmund Freud, vol. XXI. Rio de Janeiro: Imago, 1969, p. 15-79.

FREUD, Sigmund (1937) Análise terminável e interminável. In: Freud, Sigmund. Edição Standard Brasileira das Obras Completas de Sigmund Freud, vol. XXIII. Rio de Janeiro: Imago, 1969, p. 239-287.

LACAN, Jacques (1960-1961). O Seminário, livro 8: A transferência. Rio de Janeiro: Jorge Zahar, 1992. 
LACAN, Jacques (1964). O Seminário, livro 11: os quatro conceitos fundamentais da psicanálise. Rio de Janeiro: Jorge Zahar, 1998.

LAURENT, Éric. As paixões do ser. Salvador: Escola Brasileira de Psicanálise, 2000.

MILLER, Jacques-Alain. El Outro que no existe y sus comités de ética. Buenos Aires: Paidós, 2005.

MILLER, Jacques-Alain. El partenaire-síntoma. Buenos Aires: Paidós, 2008.

VOLTOLINI, Rinaldo. Educação e psicanálise. Rio de Janeiro: Jorge Zahar, 2011. 